\title{
CORRIGENDUM
}

\section{Wnt7a is a novel inducer of $\beta$-catenin-independent tumor-suppressive cellular senescence in lung cancer}

RK Bikkavilli, S Avasarala, M Van Scoyk, J Arcaroli, C Brzezinski, W Zhang, MG Edwards, MKK Rathinam, T Zhou, J Tauler, S Borowicz, YA Lussier, BA Parr, CD Cool and RA Winn

Oncogene (2015) 34, 5406; doi:10.1038/onc.2015.165

Correction to: Oncogene (2015) 34, 5317-5328; doi:10.1038/onc. 2015.2; published online 2 March 2015

The authors wish to make readers aware of a typographical error in the above paper for the amount of urethane administered to the Wnt7a mice. The amount given should read as $1 \mathrm{mg} / \mathrm{g}$ body weight not $1 \mathrm{mg} / \mathrm{kg}$ body weight.

In the Results section in page 4, the following paragraph should be amended to read:

To test this idea, we probed for the effects of urethane (ethyl carbamate)-induced lung tumor formation in wild type and Wnt7a-null mice, a prototypical model to study lung tumorigenesis. ${ }^{26-28}$ Urethane is a chemical carcinogen, which causes activating mutations in K-Ras, ${ }^{27,28}$ leading to the formation of lung tumors in mice. Several studies have highlighted a strainspecific response to urethane; for example, FVB/NJ strains are susceptible to lung tumorigenesis, whereas $\mathrm{C} 57 \mathrm{BI} / 6 \mathrm{~J}$, in contrast, are more resistant. ${ }^{26-28}$ Therefore, in our studies, wild type and Wnt7a null in FVB/NJ mice received the standard single dose of $1 \mathrm{mg} / \mathrm{g}$ body weight of urethane, whereas wild type and Wnt7a null in C57BI/6J mice received weekly injections of $1 \mathrm{mg} / \mathrm{g}$ body weight of urethane for 6 weeks. The mice were euthanized and dissected after 20 weeks (FVB/NJ strains) or 40 weeks (C57BI/6J strains) to assess the formation of lung tumors.

In the Materials and Methods section on page 10, the following paragraph should be amended to read:

Urethane treatment. Six-to-eight-week-old mice were given intraperitoneal injections of either $0.9 \%$ saline or urethane ( $1 \mathrm{mg} / \mathrm{g}$ body weight). Wild-type and Wnt7a-null mice in FVB/NJ strain received the standard single dose of urethane, whereas the wild-type and Wnt7a-null mice in $\mathrm{C} 57 \mathrm{BI} / 6 \mathrm{~J}$ strain received weekly injections of $1 \mathrm{mg} / \mathrm{g}$ body weight of urethane for 6 weeks. The control and experimental mice were weighed weekly to observe any changes in body weight until they were euthanized. The mice were euthanized and dissected after 20 weeks (FVB/NJ strains) or 40 weeks (C57BI/6J strains) to assess the formation of lung tumors. Lung tumors were counted and measured using digital calipers (Fisher Scientific, Waltham, MA, USA).

The authors apologise for any inconvenience caused by this error.

This error has now been rectified, and the corrected article appears in this issue. The html and online pdf versions have also been rectified, and now carry the corrected paper. 